Doi: 10.5212/Publ.Exatas.v.15i2.113120

\title{
TRATAMENTOS DE SOLO NO CONTROLE DE NEMATOIDES VISANDO PRODUTIVIDADE E QUALIDADE DE RAIZ EM PLANTAS DE YACON (POLYMNIA SONCHIFOLIA POEP. ENDL.)
}

\section{INCREASE IN THE PRODUCTION AND QUALITY OF YACON (POLYMNIA SONCHIFOLIA POEP. ENDL.): DIFFERENT SOIL TREATMENTS TO CONTROL NEMATODES}

\author{
Marcelo Alvares de Oliveira' ${ }^{1}$; Danilo Jacomini ${ }^{2}$ \\ ${ }^{1}$ Pesquisador Dr. Embrapa Soja, Londrina, PR, Brasil; telefone: (43)3371-6282; \\ e-mail: malvares@cnpso.embrapa..br \\ 2 Bolsista PIBIC/CNPq e Graduando em Engenharia Agronômica - FCA-UNESP- \\ Botucatu e-mail: danjacomini@gmail.com
}

\begin{abstract}
RESUMO
O yacon é tradicionalmente consumido como fruta fresca ou desidratado em diferentes graus. $\mathrm{O}$ interesse está focado tanto nas fibras solúveis como nas insolúveis (inulina). Nematoides do gênero Meloidogyne causam diminuição na produção e também fissuras e cicatrizes nas raízes, tornado-as sem valor comercial. Diante da importância que a cultura tem ganhado nos últimos anos, o objetivo do trabalho foi verificar a eficiência da aplicação de manipueira e do nematicida Carbofuran (Furadan 50G) em tratamento de solo, no controle de Meloidogyne sp., visando maior produtividade e qualidade final das raízes para a comercialização. $\mathrm{O}$ experimento foi conduzido nos canteiros experimentais do CERAT/UNESP/ Botucatu. Foram levantados doze canteiros de seis metros de comprimento, onde foram conduzidos três tratamentos (controle, manipueira e Carbofuran), com quatro repetições, para controle de nematoide. Em todos os tratamentos houve comprometimento da produção e da qualidade, sendo possível afirmar que solo e mudas isentos de Meloidogyne sp. são necessários como condições mínimas para o sucesso na produção do yacon.
\end{abstract}

Palavras-chave: Smallanthus. Nematoides. Oligofrutanos. Raízes. Yacon.

\begin{abstract}
Yacon is traditionally consumed as a fresh or dried fruit in different degrees. The interest in yacon focuses both in its soluble and insoluble (inulin) fibers. Meloidogyne nematodes cause the decrease in the production as well as cracks and scars in the roots, which makes yacon loose its commercial value. The aim of this study was to verify the efficiency of manipueira and nematicide Carbofuran in soil treatment to control nematodes and to increase the production and quality
\end{abstract}


of the roots. The experiment was conducted in experimental plots at the CERAT / UNESP / Botucatu. Twelve experimental plots with six meters were divided in three treatment areas (control, manipueira and Carbofuran) with four repetitions. In all treatments the production and quality of the roots were compromised. It was possible to conclude that both soil and seedlings free of nematodes (Meloidogyne ethiopica) are the minimum requirement for the success in the production of yacon.

Keywords: Smallanthus. Nematodes. Oligofructans. Roots. Yacon.

\section{Introdução}

Polymnia sonchifolia Poep. Endl., comumente conhecida como yacon, é uma espécie da família Asteraceae, de origem andina, sendo que esta região é o centro de diversificação de espécies desde os tempos pré-históricos. (ZARDINI, 1991). As plantas de yacon apresentam dois tipos de órgãos subterrâneos de reserva: os caules rizomatosos, responsáveis pela reprodução vegetativa da espécie, e as raízes tuberosas, nas quais são armazenados os carboidratos solúveis, em sua maioria do tipo inulina. (CASTILLO, 1982; NATIONAL RESEARCH COUNCIL, 1989). Ela é utilizada na alimentação humana, e para este fim são preferidas as raízes tuberosas mais doces, mais suculentas e menos fibrosas que os caules rizomatosos, apresentando sabor semelhante ao da pera, quando consumidas in natura. (OHYAMA et al., 1990).

O yacon foi introduzido como cultivo comercial no Brasil em 1991, em Capão Bonito, SP, pela colônia japonesa, que utiliza suas raízes in natura ou desidratadas, assim como suas folhas na forma de chá, para o tratamento contra diabetes e altas taxas de colesterol no sangue. (KAKIHARA et al. 1996).

A maturidade é alcançada entre seis e oito meses após o plantio, quando tem início a floração. Este estádio será então seguido por um período de incremento do conteúdo dos oligofrutanos nos rizóforos e raízes tuberosas, passando então para uma fase de senescência da parte aérea e dormência das partes subterrâneas. (NATIONAL RESEARCH COUNCIL, 1989). A colheita no estado de São Paulo é realizada ao redor de dez e doze meses após o plantio para fins comerciais, encontrando-se as raízes bem desenvolvidas. Ocorre, todos os anos, senescência de toda a parte aérea da planta na estação de inverno. (OLIVEIRA; NISHIMOTO, 2004).
Nieto (1991) relatou valores médios em massa seca de $3,7 \%$ de proteínas, $3,5 \%$ de cinzas, $1,5 \%$ de matéria graxa, $3,4 \%$ de fibras, $0,82 \%$ de potássio, $0,12 \%$ de fósforo e $67,8 \%$ de açúcares totais, concluindo ser um alimento altamente energético. $\mathrm{O}$ interesse está focado tanto nas fibras solúveis como nas insolúveis (inulina). As cadeias longas frutoligossacarídeos (FOS), do tipo inulina, com grau de polimerização (GP) entre três e dez, são estimulantes da proliferação das bifidobactérias, enquanto os FOS de cadeia curta de dois a cinco são comumente chamados de "neoaçúcares" (HIDAKA; EIDA, 1991; SPIEGEL et al., 1994 apud SCHORR-GALINDO; GUIRAUD, 1996).

Os frutoligossacarídeos são considerados alimentos funcionais que proporcionam bom efeito gastrintestinal, atuando no aumento de bifidobactérias benéficas do intestino. Isto se deve ao fato de que esses carboidratos resistem ao processo digestivo, não sendo hidrolisados na parte superior do trato intestinal devido à configuração de suas ligações e a outras propriedades físico-químicas. Na parte inferior do intestino eles são metabolizados pelas bactérias anaeróbicas (bifidobactérias). Este processo é conhecido por fermentação e produz energia para a proliferação das bactérias, além de gases e ácidos graxos de cadeia curta. Esses ácidos graxos são absorvidos pelo epitélio do cólon e metabolizados em diversas partes do corpo, de onde provêm baixos valores calóricos ( 1 a 3 $\mathrm{kcal} \mathrm{g}^{-1}$ ) atribuídos aos oligossacarídeos (INCOLL; BONNETT, 1993; NINESS, 1999; ALIPIO, 2000). Além disso, esses compostos apresentam grande poder edulcorante e podem ser excelentes alternativas para substituir a sacarose em dietas especiais como, por exemplo, a realizada por diabéticos.

A incidência de nematoides na cultura do yacon em nosso país tem sido relatada desde 1996, por Kakiara (GRAU; REA, 1997), causando prejuízos 
nas produções brasileiras. As raízes infectadas por nematoides de galha apresentam redução de crescimento e de tamanho, além de fissuras e cicatrizes, que inviabilizam a sua comercialização no mercado hortícola. Devido ao fato de o yacon ser propagado de forma vegetativa, através de propágulos de 60 a 80 gramas do rizóforo, possuindo de duas a três gemas, ocorreu a disseminação de nematoide pelas regiões produtoras do estado de São Paulo, sendo hoje a principal doença da cultura.

A manipueira é o líquido de aspecto leitoso e de cor amarelo-clara que escorre das raízes tuberosas da mandioca por ocasião da prensagem das mesmas, com vista à obtenção da farinha ou da fécula. É um subproduto ou resíduo da industrialização da mandioca, que fisicamente se apresenta na forma de suspensão aquosa e quimicamente como uma miscelânea de compostos, dentre os quais derivados cianogênicos, como o ácido cianídrico, cianetos e aldeídos (MAGALHÃES, 1993 apud PONTE, 2001). Ela foi originalmente testada como nematicida no tratamento de solos infestados por nematoides de galhas (Meloidogyne sp.), os quais se situam entre os mais tolerantes aos nematicidas comerciais. Na primeira investigação, a manipueira já revelou uma enérgica potencialidade nematóxica (PONTE et al., 1979 apud PONTE, 2001). Este teste envolveu plantas de quiabo (Hibiscus esculentus L.) em solos envasados que haviam sido previamente infestados por ovos e larvas de nematoides das galhas, dez dias depois tratados com manipueira. A partir de crescentes dosagens de manipueira $(0,500,750,1000 \mathrm{ml}$ por vaso, com 6 litros de solo), os autores obtiveram decrescentes porcentagens de plantas atacadas por Meloidogyne: $100,60,50$ e $30 \%$ respectivamente.

Diante da importância que a cultura tem ganhado nos últimos anos, o objetivo do trabalho foi verificar a eficiência da aplicação de manipueira e do nematicida Carbofuran (Furadan 50G) em tratamento de solo, no controle de Meloidogyne sp., visando maior produtividade e qualidade final das raízes para a comercialização.

\section{Materiais e métodos}

Os rizóforos foram coletados em Capão Bonito, SP, em 15 de julho de 2005, e levados ao Centro de
Raízes e Amidos Tropicais da UNESP em Botucatu. Foram coletados rizóforos desta localidade devido ao relato de baixa incidência de nematoide nesta área. A partir destes rizóforos foram produzidas 120 mudas para o experimento, acondicionadas em sacos plásticos, utilizando-se o substrato Plantimax ${ }^{\circledR}$. Após as mudas terem atingido aproximadamente a altura de $0,2 \mathrm{~m}$ (70 dias após o plantio dos rizóforos), em telado sob irrigação, foi feito o plantio definitivo em 4 de outubro de 2005.

O clima local é definido, de acordo com a classificação Koeppen, como Csa ou temperado chuvoso, úmido e com verões quentes, precipitação média anual de $1517 \mathrm{~mm}$ e a temperatura média anual de $20,6^{\circ} \mathrm{C}$. O solo é Latossolo Vermelho Distroférrico (LVDs) com horizonte A Moderado, a altitude é de $810 \mathrm{~m}$ e as coordenadas geográficas são latitude $22^{\circ} 52^{\prime} 47^{\prime \prime}$ S e longitude $48^{\circ} 25^{\prime} 12^{\prime \prime} \mathrm{W}$.

$\mathrm{O}$ experimento foi conduzido em canteiros experimentais do CERAT/UNESP, local em que já se cultivou yacon e com incidência de ataque de nematoides. Foram realizados tratos culturais como capinas quinzenais entre plantas e aplicação de herbicida glifosate nas entrelinhas, na concentração de $5 \mathrm{~mL}$ por litro de calda. A irrigação foi conduzida de maneira adequada, por sistema de gotejamento, ativado sempre que necessário.

Antes do plantio foi feita a análise de solo, e a partir da mesma, a calagem e a adubação necessária. Em função da análise de solo, foi adicionado e incorporado $500 \mathrm{~kg}$ de calcário em área total $\left(2500 \mathrm{~m}^{2}\right)$ um mês antes do plantio das mudas, o que correspondeu à aplicação de duas toneladas de calcário por hectare. A adubação foi feita seguindo as recomendações de Montiel (1996), apud Kruger (2003), aplicando-se 100-120-140 kg ha-1 de NPK. A adubação de plantio foi realizada aplicando-se $51 \mathrm{~g}$ por planta na cova do adubo 4-14-8, o que correspondeu a $31,3 \mathrm{~kg}$ de $\mathrm{N}$, $120 \mathrm{~kg}$ de $\mathrm{P}$ e $68,6 \mathrm{~kg}$ de $\mathrm{K}$ por hectare. Após 110 dias do plantio definitivo, foi feita a adubação de cobertura aplicando-se $0,02 \mathrm{~kg}$ por planta do adubo 20-5-20, o que correspondeu $70 \mathrm{~kg}$ de $\mathrm{N}$ e K e 17,5 $\mathrm{kg}$ de $\mathrm{P}$ por hectare.

Foram levantados 12 canteiros de seis metros de comprimento, onde foram conduzidos três tratamentos com quatro repetições. Em cada canteiro foram plantadas dez mudas, sendo que apenas as seis mudas do meio do canteiro foram consideradas 
úteis para as avaliações do experimento. No primeiro tratamento foi feita a aplicação de 6 litros da mistura ( $50 \%$ de manipueira $+50 \%$ de água) por metro linear de canteiro, e o mesmo ficou em repouso durante dez dias para posteriormente as mudas serem transplantadas (PONTE, 2001). No segundo tratamento foi feita a aplicação de 30 gramas de Carbofuran (Furadan 50G) por cova de plantio e outra aplicação da mesma quantidade após 110 dias de transplante. O terceiro tratamento foi a testemunha, onde não foi feito nenhum tipo de tratamento de solo.

Foi colhido um canteiro (uma repetição) de cada tratamento semanalmente, nos dias 16/05, $23 / 05,30 / 05$ e 06/06 de 2006. Simultaneamente às colheitas foi feita a amostragem de solo dos respectivos canteiros. As raízes tuberosas foram retiradas e limpas no local através de uma pré-lavagem. Em seguida foram encaminhadas para o laboratório do CERAT/UNESP/Botucatu, onde foi feita uma limpeza mais cuidadosa do material de campo.

$\mathrm{O}$ delineamento experimental utilizado foi o inteiramente casualizado, com quatro repetições, seguido do teste de Tukey a 5\%. Para a análise porcentagem de dano das raízes colhidas ao final do experimento foram feitas 20 repetições (20 raízes) por dia de amostragem. (NOGUEIRA, 1991).

\section{Avaliações}

As avaliações foram conduzidas nos laboratórios do Centro de Raízes e Amidos Tropicais CERAT/ UNESP/Botucatu e no laboratório do Departamento de Defesa Fitossanitária da FCA/UNESP-Botucatu. A colheita foi feita entre a $32^{\mathrm{a}}$ e a $35^{\mathrm{a}}$ semana após o plantio, seguindo orientação de Oliveira \& Nishimoto (2004). As seguintes variáveis foram avaliadas:

a) Análise nematológica do solo antes da instalação e após a colheita do experimento

Para o processamento utilizou-se $0,25 \mathrm{~L}$ de solo proveniente de uma amostra composta dos canteiros utilizados no experimento anterior aos tratamentos. Após a colheita do experimento, foram encaminhadas quatro amostras de solo de cada tratamento, sendo uma amostra de cada coleta. A análise seguiu a metodologia proposta por Jenkins (1964).

\section{b) Análise nematológica das raízes das mudas provenientes de rizóforos de Capão Bonito e das raízes colhidas ao final do experimento}

Duas mudas no estágio para transplantio (70 dias após o plantio dos rizóforos) e duas mudas acondicionadas em casa de vegetação por mais 60 dias (130 dias após o plantio dos rizóforos) foram avaliadas pelo método descrito por Dimitri (2000). Das raízes colhidas ao final do experimento foram encaminhadas quatro amostras de cada tratamento, sendo uma amostra de cada coleta.

\section{c) Massa fresca de raízes colhidas ao final do experimento por planta}

Foram avaliadas seis plantas de cada tratamento de cada repetição. Os resultados foram expressos em gramas de raiz por planta.

\section{d) Porcentagem de dano das raízes colhidas ao final do experimento}

Foram avaliadas aleatoriamente 20 raízes de cada tratamento, em cada semana de amostragem, em uma escala hedônica de 1 a 4:

1.Raiz sem dano

2.Raiz pouco danificada

3.Raiz danificada

4.Raiz muito danificada

\section{e) Perfil de açúcares em HPLC}

Para cada tratamento, em cada semana de amostragem, foi preparada uma amostra, perfazendo um total de quatro amostras por tratamento. A inulina foi extraída pelo método a quente, e os açúcares quantificados por cromatografia conforme metodologia descrita por Oliveira \& Nishimoto (2004). 


\section{Resultados e discussão}

\section{a) Análise nematológica do solo antes da instalação do experimento}

O solo apresentou uma quantidade baixa de nematoides, sendo que em $250 \mathrm{ml}$ de solo foram encontrados 6 adultos de Meloidogyne sp. e 10 adultos de Aphelenchus sp. De acordo com Dickerson et al. (2000), para o cultivo de batata em solos argilosos é considerado baixo índice de infestação até o valor 14 nematoides por $100 \mathrm{~cm}^{3}$ de solo (nível que provavelmente não causa problema para a cultura a ser implementada), isto é, uma quantidade maior do que a encontrada no experimento num volume 2,5 vezes menor de solo.

\section{b) Análise nematológica das mudas provenientes de rizóforos de Capão Bonito}

Das quatro mudas encaminhadas para laboratório, duas foram utilizadas para a análise imediata, sendo que as mesmas não apresentaram presença de adultos dos gêneros Meloidogyne e Aphelenchus. Entretanto, as outras duas mudas foram deixadas em casa de vegetação por mais 60 dias para observação do possível desenvolvimento de juvenis e ovos que ainda não apareciam nas mudas jovens. Após dois meses (21/11/2005), estas mudas foram avaliadas e apresentaram uma contaminação de 1796 nematoides do gênero Meloidogyne por 10 gramas de raiz. Esse resultado foi obtido devido à alta capacidade do nematoide de se reproduzir no interior das raízes tuberosas e rizóforos do yacon, sendo que não existem relatos de produtos químicos capazes de isentar as mudas de yacon de nematoides. Os rizóforos provenientes de Capão Bonito, embora proveniente de plantas teoricamente sadias, apresentavam juvenis e ovos de nematoides, que se desenvolveram durante o crescimento das mudas em casa de vegetação.

c) Análise nematológica do solo após a colheita do experimento

As mudas provenientes de Capão Bonito inicialmente não apresentavam a presença de nematoides adultos, entretanto, após dois meses, verificou-se um aumento muito expressivo do número, evidenciando que mesmo sem a identificação inicial dos nematoides, ovos encontravam-se presentes nos rizóforos e com o desenvolvimento das mudas os mesmos proliferaram (Tabela 1).

Tabela 1 - Número de Meloidogyne sp. adultos encontrados em 0,25 L de solo após a colheita do yacon no CERAT/UNESP/Botucatu. Maio/Junho de 2006.

\begin{tabular}{c|c}
\hline Tratamentos & $\begin{array}{c}\text { Médias do } \mathrm{n}^{\mathrm{o}} \text { de } \\
\text { nematoides adultos }\end{array}$ \\
\hline Controle & $2006,66 \mathrm{~A}$ \\
\hline Manipueira & $1880,00 \mathrm{~A}$ \\
\hline Carbofuran (Furadan 50G) & $1146,66 \mathrm{~A}$ \\
\hline
\end{tabular}

Comparações na coluna seguida de letras iguais não diferem significativamente $(\mathrm{p}>0.05)$.

DMS $=1931,11$

$\mathrm{CV} \%=45,94$

Os nematoides existentes nas mudas dos canteiros experimentais encontraram condições favoráveis para desenvolvimento, o que acarretou uma alta população de nematoides no solo em todos os tratamentos após a colheita do experimento. Portanto, mesmo o solo apresentando uma concentração inicial muito baixa de nematoides, com a introdução das mudas contendo juvenis e ovos, a disseminação e proliferação de indivíduos ficou muito evidente, sendo que, de uma contagem inicial do solo de 6 indivíduos por $250 \mathrm{ml}$ de solo, este número alcançou números superiores a 1100 indivíduos por $250 \mathrm{ml} \mathrm{em}$ todos os tratamentos (Tabela 1).

Os níveis de nematoides encontrados são considerados extremamente altos, com base em Dickerson et al. (2000). Os resultados mostraram que nenhum tratamento apresentou eficácia no controle de nematoides no solo e nem mesmo o tratamento com Furadan, que era para dar um período residual para contenção da disseminação dos nematoides.

\section{d) Análise nematológica das raízes após a colheita do experimento}

Devido à presença de nematoides nas mudas provenientes de Capão Bonito, encontrou-se uma alta população de nematoides nas raízes após a colheita do experimento em todos os tratamentos (Tabela 2). 
Tabela 2 - Número de Meloidogyne sp. adultos encontrados em 10 gramas de raiz de yacon, após a colheita no CERAT/UNESP/Botucatu. Maio/junho de 2006.

\begin{tabular}{c|c}
\hline Tratamentos & $\begin{array}{c}\text { Médias do } \mathrm{n}^{\circ} \text { de nematoides } \\
\text { adultos }\end{array}$ \\
\hline Controle & $8686 \mathrm{~A}$ \\
\hline Manipueira & $7673 \mathrm{~A}$ \\
\hline Carbofuran (Furadan 50G) & $6353 \mathrm{~A}$ \\
\hline
\end{tabular}

Comparação na coluna seguida de letras iguais não diferem

$\mathrm{DMS}=13326,27$ significativamente $(\mathrm{p}>0.05)$.

$\mathrm{CV} \%=70,25$

A instalação da cultura gera um meio favorável ao desenvolvimento e reprodução dos nematoides, que rapidamente se multiplicaram dentro dos rizóforos e raízes de yacon. Verificou-se aumento de mais de três vezes no número de indivíduos, para todos os tratamentos, quando comparado com as mudas deixadas por 60 dias na casa de vegetação (1796 nematoides por 10 gramas de raiz).

A ação nematicida esperada pelo tratamento com Carbofuran (Furadan 50G), devido ao seu poder residual depois da absorção pela planta, não foi constatada mesmo tendo sido aplicado uma vez na cova de plantio e outra vez quando a cultura completou 110 dias no campo. Os resultados mostraram que nenhum tratamento apresentou eficácia no controle de nematoides nas raízes.

\section{e) Massa fresca de raízes colhidas ao final} do experimento por planta

Os valores de massa fresca de raiz por planta não diferiram significativamente entre os tratamentos (Tabela 3).

Tabela 3 - Valores de peso médio de raízes (em gramas) por planta de yacon após a colheita no CERAT/ UNESP/Botucatu. Maio/Junho de 2006.

\begin{tabular}{c|c}
\hline Tratamentos & $\begin{array}{c}\text { Média dos pesos das raizes } \\
\text { por planta }\end{array}$ \\
\hline Controle & $851,875 \mathrm{~A}$ \\
\hline Manipueira & $845,167 \mathrm{~A}$ \\
\hline Carbofuran (Furadan 50G) & $499,583 \mathrm{~A}$ \\
\hline
\end{tabular}

Comparação na coluna seguida de letras iguais não diferem significativamente $(\mathrm{p}>0.05)$.

$\mathrm{DMS}=532,80$

$\mathrm{CV} \%=105,13$
Com o espaçamento utilizado, a estimativa de produtividade dos tratamentos controle e manipueira foram de aproximadamente 14 ton ha ${ }^{-1}$. Já para o tratamento com Carbofuran (Furadan 50G), esta estimativa foi menor ainda, com 8,3 ton $\mathrm{ha}^{-1}$. Tais produtividades podem ser consideradas baixas quando comparadas às produtividades de $100 \mathrm{t} / \mathrm{ha} \mathrm{e}$ $45 \mathrm{t} /$ ha obtidas por Kakihara et al. (1996) e Oliveira \& Nishimoto (2004), respectivamente.

\section{f) Porcentagem de dano das raízes colhidas ao final do experimento}

$\mathrm{Na}$ colheita as raízes não apresentaram valor comercial, pois além do porte reduzido das plantas, que acarretou uma baixa produção, ocorreu a presença de fissuras e rachaduras, tornando inviável sua comercialização in natura (Figura 1).
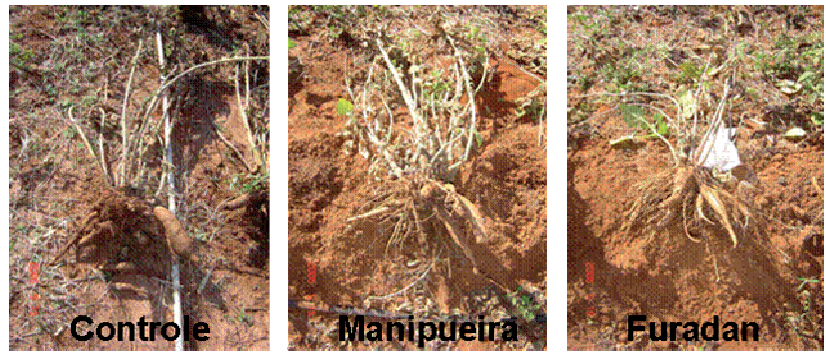

Figura 1 - Raízes de yacon após a colheita do experimento nos canteiros experimentais do CERAT/ UNESP/Botucatu. Maio/Junho de 2006.

Todos os tratamentos apresentaram uma maior porcentagem de raízes muito danificadas, seguida de raízes danificadas ou pouco danificadas (Tabela 4).

Tabela 4 - Porcentagem média de raízes de yacon em função do nível de dano causado por Meloidogyne sp.e submetidas a diferentes tratamentos de solo.

\begin{tabular}{|c|c|c|c|c|c|}
\hline Tratamentos & $\begin{array}{c}\text { Raizsem } \\
\text { Dano }\end{array}$ & $\begin{array}{l}\text { Raiz pouco } \\
\text { Danificada }\end{array}$ & $\begin{array}{c}\text { Raiz } \\
\text { Danificada }\end{array}$ & $\begin{array}{l}\text { Raiz muito } \\
\text { Danificada }\end{array}$ & $\begin{array}{c}\text { DMS } \\
(\%)\end{array}$ \\
\hline Controle & $1,25 \mathrm{Ab}$ & $31,25 \mathrm{Aa}$ & $26,25 \mathrm{Aa}$ & $41,25 \mathrm{Aa}$ & \multirow{4}{*}{$\begin{array}{l}17,20 \\
17,20 \\
17,20\end{array}$} \\
\hline Manipueira & $6,25 \mathrm{Ab}$ & $17,50 \mathrm{Ab}$ & $21,25 \mathrm{Ab}$ & $55,00 \mathrm{ABa}$ & \\
\hline $\begin{array}{c}\text { Carbofuran } \\
\text { ( F u rad a n } \\
50 \mathrm{G})\end{array}$ & $0,00 \mathrm{Ac}$ & $17,50 \mathrm{Ab}$ & $23,75 \mathrm{Ab}$ & $58,75 \mathrm{Ba}$ & \\
\hline DMS (\%) & 15,61 & 15,61 & 15,61 & 15,61 & \\
\hline
\end{tabular}

Comparação na linha seguida de letra minúscula não difere significativamente $(\mathrm{p}>0,05)$.

Comparação na coluna seguida de letra maiúscula não difere significativamente $(\mathrm{p}>0,05)$.

$\mathrm{CV}=36,36 \%$ 
A porcentagem de raízes sem dano encontradas em todos os tratamentos foi muito baixa e sem a ocorrência de diferenças significativas entre os tratamentos. Assim sendo, todos os tratamentos apresentaram uma quantidade mínima de raízes com valor comercial para ser negociada como hortícola, verificando a ineficiência de todos os tratamentos de solo no controle dos nematoides do tipo Meloidogyne sp. O tratamento com Carbofuran (Furadan 50G), com o qual se esperava um residual devido a sua aplicação no plantio e também após 110 dias, foi o que apresentou a maior porcentagem de raízes muito danificadas, confirmando a ineficiência do produto no controle.

\section{g) Perfil de açúcares em HPLC}

Analisando o perfil de açúcares das raízes de yacon submetidas aos diferentes tratamentos de solo, verificou-se que não houve interferência dos tratamentos no perfil de açúcares, e em todos os tratamentos a inulina apresentou uma porcentagem de área em relação à área total do cromatograma de açúcar variando entre 49,12 e 59,78\% (Tabela 5).

Tabela 5 - Quantidade em gramas por quilo de matéria fresca de inulina, glicose e sacarose das raízes tuberosas e quantidade média de inulina por planta baseado no valor da massa fresca média durante as semanas que sucederam o plantio.

\begin{tabular}{c|c|c|c|c}
\hline Tratamentos & $\begin{array}{c}\text { Sacarose } \\
\left(\mathrm{g} \mathrm{kg}^{-1}\right. \\
\left.\mathrm{de} \mathrm{MF}^{1}\right)\end{array}$ & $\begin{array}{c}\text { Glicose } \\
\left(\mathrm{g} \mathrm{kg}^{-1}\right. \\
\left.\mathrm{de} \mathrm{MF}^{-1}\right)\end{array}$ & $\begin{array}{c}\text { Frutose } \\
\left(\mathrm{g} \mathrm{kg}^{-1} \mathrm{de}\right. \\
\left.\mathrm{MF}^{1}\right)\end{array}$ & $\begin{array}{c}\text { Inulina } \\
\text { (porcentagem de área em relação à } \\
\text { área total do cromatograma de açúcar) }\end{array}$ \\
\hline Controle & $10,48 \mathrm{~A}$ & $17,83 \mathrm{~A}$ & $31.86 \mathrm{~A}$ & $49,12 \mathrm{~A}$ \\
\hline Manipueira & $7,46 \mathrm{~A}$ & $13,90 \mathrm{~A}$ & $23.38 \mathrm{~A}$ & $59,78 \mathrm{~A}$ \\
\hline $\begin{array}{c}\text { Carbofuran } \\
\text { (F u r a d a n } \\
\text { 50G) }\end{array}$ & $6,19 \mathrm{~A}$ & $15,97 \mathrm{~A}$ & $30.51 \mathrm{~A}$ & $59,48 \mathrm{~A}$ \\
\hline Média & 8,04 & 15,90 & 28,58 & 56,13 \\
\hline $\begin{array}{c}\text { DMS } \\
\text { CV\% }\end{array}$ & 82.37 & 6,96 & 16,13 & 11,41 \\
\hline
\end{tabular}

${ }^{1} \mathrm{MF}=$ Matéria Fresca

Comparação na coluna seguida de letra maiúscula não difere significativamente $(\mathrm{p}>0,05)$.

Verificou-se um teor de frutose mais elevado em todos os tratamentos, em relação ao de sacarose e glicose. Estes resultados diferem dos encontrados por Oliveira \& Nishimoto (2004), que observaram teores de sacarose maiores que os de glicose e de frutose. É possível que esta diferença tenha ocorrido devido às alterações metabólicas causadas na planta pelo intenso ataque de nematoide.

As porcentagens de área em relação à área total do cromatograma de inulina encontradas neste estudo estão semelhantes às percentagens observadas por Oliveira \& Nishimoto (2004), que relataram valores variando de 54,48 a 69,47\% da área total do cromatograma de açúcar, e por Seminario et al. (2003), que afirmam que as raízes possuem de 50 a $70 \%$ de frutoligossacarídeos.

\section{Conclusões}

Os tratamentos de solo com manipueira e com Carbofuran (Furadan 50G) foram ineficientes no controle de nematoides Meloidogyne sp. Em todos os tratamentos houve comprometimento da produção e da qualidade das raízes de yacon, sendo possível afirmar que solo e mudas isentos de nematoides (Meloidogyne ethiopica) são necessários como condições mínimas para o sucesso na produção do yacon.

\section{REFERÊNCIAS}

ALIPIO, R. Oligossacarídeos e suas propriedades funcionais. Food Ingredients, São Paulo, n. 7, p. 94-95, 2000.

CASTILLO, R. O Andean crops in Equador: collecting, conservation and characterization. FAO/IBPGR. Plant Genetic Research, v. 77, p.35-36, 1982.

DICKERSON, O. J.; BLAKE, J. H.; LEWIS, S. A. Nematodes guidelines for South Carolina. Clemson: Clemson extension, 2000. 36p. Disponível em: <http://virtual.clemson.edu/ groups/psapublishing/Pages/Plntpath/EC703.pdf $>$. Acesso em 12 abr. 2006.

DIMITRY, T. Nematologia agrícola aplicada. 2. ed. Jaboticabal: Funep, 200. 473p.

GRAU, A,; REA, J. Yacon (Smallanthus sonchifolia Poepp. \& Endl.) H Robinson. In: HERMMAN, M.; HELLER, J. Andean roots and tube: ahipa, arracacha, maca and yacon. Roma: IPGRI, 1997. p. 199-242.

INCOLL, L. D.; BONNETT, G. D. Fructans in the Compositae - a short review. In: CALIGARI, P. D. S., HIND, D. J. N. (Eds). Compositae: Biology \& Utilization. Proceedings 
of the International Compositae Conference. Royal Botanic Gardens, Kew. v. 2, p. 401-413,1993.

JENKINS, W. R. A rapid centrifugal - flotation technique for separating nematodes from soil. Plant Diasease Report, v. 48, 1964. p. 692.

KAKIHARA,T. S.; CÂMARA, F. L. A.; VILHENA, S. M. C. Cultivo e industrialização de yacon (Polymnia sonchifolia): uma experiência brasileira. In: CONGRESSO LATINO AMERICANO DE RAÍZES TROPICAIS, 1 e CONGRESSO BRASILEIRO DE MANDIOCA, 9, 1996. São Pedro. Anais... São Pedro, 1996. Resumo n.148.

KRUGER, F. G. Q. Adubação mineral, orgânica e biodinâmica de yacon (Polymnia sonchifolia Poep \& Endl): rendimento, qualidade e armazenamento. 2003. $211 \mathrm{f}$. Tese (Doutorado em Horticultura) - Faculdade de Ciências Agronômicas, Universidade Estadual Paulista, Botucatu, 2003.

NATIONAL RESEARCH COUNCIL. Lost crops of the incas: little-known plants of the Andes with promise for worldwide cultivation. Washington: Academy Press, 1989. $415 p$.

NIETO, C. C. Studius agronomicos y bromatológicos em "jicama" (Polymnia sonchifolia Polp. Endl.). Archivos Latinoamericanos de Nutrición, Caracas, v. 41, p. 21321,1991 .

NINESS, K. R. Inulin and oligofructose: What are they? Journal of Nutrition, v. 129, n. 7, p. 402-6, 1999.

NOGUEIRA, M. C. S. Curso de estatística experimental aplicada à experimentação agronômica. Piracicaba, Universidade de São Paulo, 1991. 168p.

OHYAMA, T. et al. Composition of storage carbohydarte in tuber of yacon (Polymnia sonchifolia). Soil Science and Plant Nutrition, v. 36, p. 167-71, 1990.

OLIVEIRA, M. A., NISHIMOTO, E. K. Avaliação do desenvolvimento de plantas de yacon (Polymnia sonchifolia) e caracterização dos carboidratos de reservas em HPLC. Brazilian Journal of Food Technology, Campinas, v.7, n.2, p.215-220, 2004.

PONTE, J. J. Uso da manipueira como insumo agrícola. In: CEREDA, M. P. et al. Manejo de subprodutos da industrialização da mandioca. São Paulo: Fundação Cargil, 2001. p.80-95.

SCHOR-GALINDO, S.; GUIRAUD, J. P. Sugar potencial of differents jerusalém artichoke cultivars according to harvest. Bioresouce Technology, Oxford, v.60, p.15-20, 1997.

ZARDINI, E. Ethnobotanical notes on "yacon" Polymnia sonchifolia" (Asteraceae). Encon. Bot., v. 45, p. 72-85, 1991. 